\title{
Os despachantes documentalistas na era do profissionalismo organizacional ${ }^{1}$
}

Maria da Gloria Bonelli

Detetive $^{2}$

Tive tive

Detetive

Meu pai é dete

Tive tive

Detetive

Meu pai é dete

Tive tive

Detetive

Meu pai é detetive

Mas o teu é despachante! [refrão]

Meu pai é detetive

Enfrenta broncas legais

Teu pai é despachante

E não faz nada de mais

Meu pai é detetive
Prende bandido e traficante

Teu pai é um cagalhão

Que se esconde

Atrás de estante

[refrão]

Meu pai é detetive

Entrou na casa do ladrão

Deu um tiro a queima roupa

Que quebrou a televisão

Teu pai é despachante

E é um carinha simplório

Não despacha nem macumba

E tem medo de velório $[\ldots]$

COMUNIDADE NIN-JITSU

1. Esta pesquisa contou com o apoio do CNPq, Edital Universal. Agradeço a colaboração no trabalho de campo de Lucas Martins Stigliano, Karen Borelli e Lerisson Christian Nascimento, bem como a supervisão da aplicação dos questionários e o tratamento dos dados, realizados por Camila de Pieri Benedito, e a consultoria técnica da colega Fabiana Luci de Oliveira. Agradeço também os documentos cedidos pelas lideranças dos despachantes, além da disposição de cooperarem com a pesquisa, manifestada por todos aqueles que concederam entrevistas e responderam questionários.

2. Disponível em https://www.letras.mus.br/comunidade-nin-jitsu/45344, consultado em 27/5/2016. 
Introdução

Os despachantes não tiveram uma presença de destaque no imaginário social. Sua visibilidade na música ou literatura brasileira é esparsa. Outras ocupações administrativas de nível médio encontraram mais espaço simbólico na cultura nacional, como os escrivães e escreventes.

Trata-se de ocupação que acompanhou o colonialismo ibérico, chegando cedo ao Brasil. Inicia-se com o despacho alfandegário, durante o período colonial, envolvendo a contagem de escravos desembarcados para controle da metrópole. Posteriormente, incorpora os despachos de assuntos relacionados com a construção do Estado no Brasil imperial. Em 24 de outubro de 1854, dom Pedro II regulamenta o quadro de despachantes municipais e suas atribuições, como a cobrança de impostos, a legalização de imóveis, de estabelecimentos e de veículos, entre outros assuntos. Na República, essa divisão consolida-se com a separação em duas ocupações: os despachantes de alfândega, atualmente despachantes aduaneiros, e os despachantes oficiais, hoje despachantes documentalistas ${ }^{3}$.

Ao longo desses séculos, com a descentralização da República, a atividade deixa de ser exclusividade do poder central, e várias atribuições passam a ser concedidas pelos governos estaduais e municipais. Isso produziu mais especialização no processamento de documentos, diferenciando identificações coletivas entre os despachantes. Por exemplo, aqueles que lidam com o trânsito, os que obtêm alvarás e os que trabalham com a emissão de passaportes e vistos.

Os despachantes atuam perante órgãos federais, estaduais e municipais, tendo em comum a dependência em relação ao Estado, que controla e fiscaliza o serviço nesses diversos níveis. Nos últimos dez anos, os despachantes documentalistas organizados em conselhos federais e regionais buscaram seguir estratégias de profissionalização. Isso decorreu da redução de suas atribuições, com a integração dos serviços públicos para emissão de documentos em agências terceirizadas. Em São Paulo, essa nova forma do governo gerenciar o acesso da população à cidadania documentada surgiu com o Poupatempo, em 1996, cujas primeiras unidades no estado começaram a funcionar em 1997. Essa experiência foi influenciada por programas semelhantes, criados em 1995: o Serviço de Atendimento ao Cidadão, do governo da Bahia, e o Rua da Cidadania, da prefeitura municipal de Curitiba (Teciano, 2014).

Os despachantes documentalistas intermediaram a relação entre o Estado e sociedade para obtenção de documentos por mais de cem anos, refletindo como

3. Levantamento histórico gentilmente disponibilizado pelo procurador do Conselho Federal dos Despachantes Documentalistas do Brasil (CFDD-BR), Rodolfo Cesar Bevilácqua. 
essa prática foi socialmente produzida. Os funcionários das repartições públicas de emissão de documentos preferiam lidar com o despachante que preenchesse corretamente cinquenta documentos e estabelecesse vínculos e reciprocidades com eles do que atender as solicitações no varejo de pessoas que desconheciam os procedimentos e as nuances dessa rotina. Os despachantes souberam reter esse poder, mantendo-se no controle dos serviços de despacho de documentos por tanto tempo porque as pessoas eram privadas do direito de obtê-los com agilidade por conta de entraves burocráticos visando o controle social. Também conseguiam ampliar esse poder tornando mais pessoais as relações com os servidores que viabilizavam “jeitinhos" para atender os clientes.

A concepção que predominou na expedição dos documentos de trânsito, identificação e passaporte relacionava o recolhimento de taxas para a constituição de recursos financeiros públicos com o controle de polícia sobre essas parcelas da população. No que diz respeito ao trânsito, esse vínculo muda em 2011, com a Secretaria Estadual de Segurança Pública de São Paulo, deixando de incorporar o Departamento Estadual de Trânsito (Detran-SP), que é transferido para a Secretaria Estadual de Planejamento e Gestão. Os laços que se estabeleceram entre despachantes, servidores dessas repartições e Polícia Civil desde os anos de 1940 deixaram de ser funcionais diante do surgimento de novas formas de fornecer documentos ao público. O modelo ibérico que sustentou o controle colonial adequou-se no século xx, vinculando Estado e sociedade por meio dos policiais e dos despachantes. No século XXI, esse padrão cede lugar aos processos globalizantes de gestão pública do acesso à cidadania documentada, com a terceirização dos serviços de identificação e de trânsito para as empresas que ganham as concorrências locais do Poupatempo e para os bancos que recolhem os pagamentos dos impostos e das multas.

O deslocamento na posição que os despachantes ocupavam no labirinto burocrático veio acompanhado do declínio do grupo e de novos significados na sua representação social ${ }^{4}$. O "jeitinho" para obter o documento era um elo entre a sociedade e o Estado que dava poder, sentido e visibilidade a eles. Tal percepção coletiva foi mudando quando a intermediação deixou de ser necessária para o atendimento. As duas passagens a seguir ilustram esse percurso.

4. A pesquisa de Mathieu-Fritz e Bercot (2008) sobre as mudanças nas representações sociais em torno do prestígio das profissões e de suas falhas aborda essa problemática em uma perspectiva interacionista. A dupla analisa as persistentes representações negativas dos huissier de justice (grupo profissional na justiça francesa que combina atividades jurídicas, como a mediação de conflitos, com a certificação, a notificação, a cobrança de dívidas e a execução de decisões dos tribunais), a desvalorização relativa dos cirurgióes e a invisibilidade relativa dos sociólogos. 
Do lado do malandro, e como o seu oposto social, temos a figura do despachante, esse especialista em entrar em contato com as repartições oficiais para a obtenção de documentos que normalmente implicam as confusões que mencionei linhas antes, ao descrever detalhadamente o “jeitinho". O despachante, como figura sociológica, só pode ser visto em sua enorme importância quando novamente nos damos conta dessa enorme dificuldade brasileira de juntar a lei com a realidade social diária. Assim, o despachante parece mais um padrinho. Tal como o padrinho, ele é um mediador entre a lei e uma pessoa. Do mesmo modo que um patrão deve dar emprego e boas condições de trabalho a seus empregados, o despachante deve guiar seus clientes pelos estreitos e perigosos meandros das repartições oficiais, fazendo com que sigam o caminho certo. Só que o despachante é um padrinho para baixo. Digo para baixo porque as classes média e alta do Brasil têm verdadeira aversão a tudo que a faça sentir-se como pessoa comum, indivíduo sujeito a rejeiçôes e desagradáveis encontros com autoridades sem o menor traço de boa vontade. Assim, se não se tem um amigo ou uma relação que possa imediatamente facultar o "jeitinho", contrata-se um despachante, que realiza precisamente essa tarefa (DaMatta, 1984, p. 87).

Algo de bom acontece no Brasil: nos últimos três meses, renovei minha carteira de motorista, meu passaporte e meu visto americano sem precisar recorrer a um despachante (empresário David Zylbersztajn, coluna de Lu Lacerda, Veja, 27/7/2011, p. 58).

Em vez de facilitadores do acesso, a condenação moral do trabalho sujo (Hughes, 1984) veio para o primeiro plano na representação simbólica sobre os despachantes. Estando a ocupação frágil em termos da necessidade social de seu conhecimento e com poucos recursos de poder político e profissional, rapidamente caminhou de sua restrita visibilidade para uma imagem pública marcada pelos julgamentos negativos. A perda de valor profissional refletiu-se no valor social individual, tornando os despachantes mais vulneráveis ao estigma da corrupção do que outros grupos profissionais com os quais eles se relacionam nos órgãos públicos. As redes que ligam sociedade e Estado, alimentando o neopatrimonialismo ${ }^{5}$ o uso privado do bem público são mais resistentes quando o valor social da profissão é maior.

A essa imagem atribuída, os despachantes buscam construir-se pelo discurso do profissionalismo e pelas estratégias de profissionalização que ampliam poder, mas não possuem consenso sobre como operacionalizar isso.

5. Segundo Domingues (2008), três elementos do neopatrimonialismo devem ser destacados: (1) embora tenha no Estado o fulcro de sua realização, ele se conecta também à atuação dos agentes societários; (2) o caráter moderno e modernizador do patrimonialismo contemporâneo, sendo o desenvolvimento econômico e social central à sua existência; (3) lógica dual no funcionamento de Estados, com lógica racional-legal explícita e lógica patrimonial atuando oculta, com a corrupção constituindo elemento perverso do neopatrimonialismo e agindo informalmente no aparelho de Estado com seus vínculos na sociedade. 
Os grupos que estão à frente do sistema CFDD (Conselho Federal dos Despachantes Documentalistas)/CRDDs (Conselhos Regionais de Despachantes Documentalistas) têm por referência outros órgãos profissionais, como o Conselho Federal de Administração e a Ordem dos Advogados do Brasil, que regulamentaram o exercício da atividade com base na reserva de mercado, fiscalizando as práticas autônomas, assalariadas ou em sociedade empresarial. Há também grupos de despachantes organizados em associações profissionais que contestaram o formato dos conselhos com controle sobre o mercado, tendo por objetivo promover a Federação dos Despachantes.

Este estudo aborda as seguintes questôes:

- O deslocamento do modelo neopatrimonial de fornecer documentos aos cidadãos para o downsizing, que resulta na criação do Poupatempo, mais adequado à padronização dos processos globalizantes da cidadania documentada.

- O perfil socioeconômico e profissional dos despachantes atualmente e as percepções sobre a atividade.

- As lutas concorrenciais em torno das possibilidades de profissionalização e os limites do discurso do profissionalismo.

O caso dos despachantes é enfocado como contraponto ao modelo bem-sucedido da profissão de advogado para entender os obstáculos que se interpõem ao processo de profissionalização daquela ocupação. O contraste entre esses grupos profissionais é expresso pela distinção entre o exercício sagrado da defesa de direitos e a prática profana dos despachos de documentos, entre a produção social da norma e a produção social do desvio (Becker, 2009).

A perspectiva metodológica adotada é a abordagem multimétodos, com realização de survey, entrevistas qualitativas, observação e análise de fontes primárias e secundárias. Teoricamente, três enfoques analíticos foram mobilizados na construção do argumento: a definição de profissão segundo Saks (2012), que se centra nas lutas por monopólios em vez de domínio de expertise; a vertente discursiva do profissionalismo organizacional, conceituada por Evetts (2013) e Muzio e Kirkpatrick (2011); e os conceitos de trabalho sujo e instituições bastardas, aprofundados na obra de Hughes (1984).

Profissão, profissionalismo e trabalho sujo

Este tópico articula as abordagens teóricas que jogam luz sobre o processo de profissionalização que os despachantes estão vivenciando, focalizando seus limites e possibilidades. 
Saks (2012) revisou o debate sobre a definição de profissão, propondo redirecionar a ênfase no conhecimento e na expertise, para priorizar a perspectiva neoweberiana sobre a delimitação de fronteiras com base no fechamento do mercado. Para o autor, a perspectiva taxonômica marcou os estudos anglo-americanos das profissões enquanto o foco foi a classificação desses grupos, enfatizando o conhecimento e a expertise como fatores a darem força e estabilidade a elas, naturalizando tal característica como o tipo ideal de profissão. Vários enfoques questionaram a concepção funcionalista, que sofreu críticas quanto à sua consistência analítica e seus vieses ideológicos. Pesquisas mostraram o impacto de fatores sociopolíticos na diferenciação de processos de profissionalização de ocupações que detinham o mesmo grau de conhecimento. Para Saks, a abordagem neoweberiana relaciona a profissionalização com o poder e os interesses de mercado, mas em vez de limitar seu escopo a isso, acrescenta as dimensões sociopolíticas e ideológicas para a análise do sucesso e do fracasso desses processos. Ele considera as fronteiras entre os grupos profissionais flexíveis e fluidas, demandando uma visão mais holística das questões que as influenciam, para além das explicações centradas nas mudanças no conhecimento e na expertise que os grupos detêm. Nessa direção, as profissões não se reduzem a ocupações que produzem e controlam conhecimentos especializados, mas se ampliam para a inclusão dos processos de profissionalização com base nas lutas por controle exclusivo da prática, como é o caso dos despachantes.

Evetts (2013) é crítica tanto do enfoque neoweberiano, que se restringe ao fechamento de mercado, como da perspectiva de prosseguir na análise da definição do que seja uma profissão, considerando-a pouco produtiva. No lugar de discutir essas definições, ela propõe olhar os processos de profissionalização, em especial o profissionalismo. Freidson (2001) conceituou o profissionalismo em contraste com as lógicas que orientam o mercado e as organizações burocráticas. Evetts (2012) caminhou na direção oposta, de mostrar como essas distinções não davam contam de compreender grupos profissionais contemporâneos. Ela dá relevância aos sentidos atribuídos ao profissionalismo concebendo-o como: (a) um valor normativo, cuja conotação positiva é um fator a produzir identificação coletiva; (b) uma ideologia atrativa ao grupo profissional, na qual predomina a defesa de seu interesse específico, gerando nos críticos a visão negativa sobre essa forma de organização do trabalho; (c) um discurso construído principalmente de cima para baixo, no qual gerentes, empregadores e o Estado procuram produzir comportamentos e desempenhos entre os trabalhadores, em especial das ocupações de serviços. Para ela, os dois primeiros sentidos relacionam-se ao profissionalismo ocupacional, aquele que foi mais abordado no campo de estudo como promovendo processos de profissionalização oriundos de dentro do grupo. O terceiro significado é mais característico do profissionalismo 
organizacional, que discursivamente fomenta práticas de profissionalização vindas de cima. A autora atribui temporalidade à forma como a sociologia se debruçou sobre o estudo das profissões, da profissionalização e do profissionalismo, apontando a relevância de se priorizar os dois últimos fenômenos sobre o primeiro e de se aprofundar a análise pouco explorada do profissionalismo organizacional, que combina tipos ideais construídos separadamente na literatura especializada.

O processo de profissionalização que os despachantes tentam viabilizar é instigante para a sociologia das profissões, porque ao manusearem as classificações sobre profissionalismo, que produzem hibridismos na tipologia, eles permitem identificar possibilidades de refinamento teórico da abordagem.

A divisão moral do trabalho de despacho de documentos é analisada sob o prisma do mandato informal que as "pessoas de bem" delegam a especialistas, distanciando-se da execução dos serviços de documentação em órgãos públicos, envolvendo ou não trabalho sujo.

Segundo Hughes, toda sociedade com certa complexidade delega trabalho sujo para ser feito por especialistas que assumem essas tarefas. Em geral, quem delega o dirty work pertence aos grupos estabelecidos na sociedade que transferem esse trabalho àqueles que se organizam em torno de uma contramoral que justifica a execução dos serviços junto aos grupos percebidos como outsiders (Hughes, 1984, pp. 94-95). O trabalho sujo pode ser de diversos tipos, como o extermínio de judeus pelos nazistas, a implementação de condições desumanas de encarceramento nos presídios ou a delegação de tarefas desvalorizadas pelas profissões superiores a outros grupos profissionais ${ }^{6}$.

As sociedades possuem instituições legítimas e instituições bastardas; estas executam tarefas consideradas desviantes, muitas vezes sob a conivência daquelas. A prostituição seria a instituição bastarda que vive na sombra do casamento, a instituição legítima. O câmbio negro, as apostas, a receptação de mercadorias, a pirataria e a evasão de divisas tomam formas organizadas semelhantes às das instituições oficiais (Idem, p. 99). O “jeitinho" praticado por despachantes para desobstruir a liberação de documentos caracteriza-se como instituição bastarda, mas funciona como um mandato informal que instituições legítimas e "pessoas de bem" delegam a esta ocupação quando contratam tais serviços. Preencher formulários, reunir documentos, levar veículos para vistorias, levantar multas, enfrentar filas em bancos e repartições constituem-se no trabalho sujo lícito, nas tarefas desvalorizadas que outras profissões, como o direito e a administração, delegaram aos despachantes; pagar propina para "dar um jeitinho" está no âmbito do trabalho sujo ilícito. Ambos envolvem clientes, despachantes,

6. Sobre os usos do conceito dirty work, ver Arantes (2011). 
prepostos, funcionários, autoridades públicas, entre outros. Esses atores produziram socialmente a norma e o desvio na prestação de serviços de despacho de documento.

A matriz institucional da qual faz parte a divisão do trabalho em torno do trânsito tornou-se mais complexa, envolvendo novas concepções sobre o que é esse trabalho e como ele deveria ser, assim como qual mandato foi concedido pelo público para sua execução, como tal execução pode ser alcançada e quem vai executar cada tarefa, com que responsabilidade e recompensa. Uma mudança nessa matriz altera a relação entre instituições legítimas e bastardas e o mandato que as "pessoas de bem" delegam aos executores do trabalho sujo, além de colocar em disputa o que cabe a cada ocupação nessa nova divisão, quem ficará no centro ou na periferia, nas posições de mais ou menos prestígio, de mais ou menos escrúpulos (Idem, pp. 309-310).

As mudanças institucionais que ocorreram na divisão do trabalho do trânsito, tornando-a mais complexa, levaram o grupo dos despachantes a deslocar-se da posição de quem recebe a delegação do trabalho sujo para o lugar que busca a profissionalização, contrapondo-se à desvalorização moral e social da ocupação. Os grupos estabelecidos e as "pessoas de bem" já não precisam desses serviços como antes, questionando o mandato informal que persistiu ao longo do século.

Em contraste com os despachantes, a advocacia mantem seu mandato moral e prestígio social como instituição legítima. Os advogados constituem-se em um grupo com capitais políticos, sociais e profissionais expressivos que vão além do projeto de controle do mercado, incluindo em seu ideário valores sobre o Estado e a nação. $\mathrm{O}$ profissionalismo cívico (Halliday, 1999) é essa via de mão dupla, na qual a profissão não se restringe ao projeto que o Estado tem para ela, mas também os profissionais poderosos têm um projeto para o Estado, o que acentua os aspectos normativos do profissionalismo como valor ocupacional.

No caso dos despachantes, observa-se a ausência desses capitais e de um ideário predominante, como o do profissionalismo cívico, capaz de construir uma visão comum sobre como se organizar e se relacionar com o Estado. O processo de profissionalização em curso enfrenta lutas concorrenciais no interior do grupo, não se constituindo um ideário estabelecido que dê coesão a eles, como os valores do profissionalismo ocupacional deram aos advogados. As disputas classificatórias envolvem a construção social da atividade dos despachantes como desvio e como norma. Ao longo do século Xx predominou a percepção de que o despacho de documentos facilitava a vida dos clientes e o trabalho dos funcionários das repartições públicas, "limpando" o trabalho sujo envolvido na atividade.

A experiência histórica do grupo dos despachantes é de ser regulado pelo Estado, por meio dos órgãos públicos municipais, estaduais ou federais, que controlavam até mesmo o número de credenciais que seriam fornecidas para a prática da atividade. 
Embora o modelo das profissões com recursos de poder como a advocacia enfatize a autonomia, permanece forte entre os despachantes o sentimento de que o Estado lhe deve mais atenção - eles querem apoio governamental para impulsionar o projeto profissional. A quebra da longa relação de dependência não está sendo substituída pelo fortalecimento do grupo, mas pela percepção de abandono pelo governo, que desmontou as formas tradicionais como se operavam facilidades diante de uma burocracia complexa.

McClelland (1990), estudando a advocacia, relacionou o caso anglo-americano à profissionalização vinda de dentro do grupo profissional e o caso alemão como "profissionalização vinda de cima“, do Estado. Como demonstrado por Evetts (2013), a iniciativa de cima também pode vir de corporações, como ocorre hoje nas empresas, partindo de grupos poderosos que articulam discursos do profissionalismo, sem a base institucional.

Por outro lado, o profissionalismo como discurso - e seu desdobramento no profissionalismo organizacional (Evetts, 2013) - desempenha principalmente o papel oposto do profissionalismo como valor normativo: não unifica o grupo, fragilizando-o diante dos segmentos de elite que articulam visões críticas a tal ideário, na perspectiva de gerar práticas sujeitas ao controle das cúpulas das organizações privadas e dos órgãos públicos. A força do profissionalismo organizacional vem de cima e de fora do campo das profissóes: seu poder origina-se no âmbito da política ou da esfera econômica e social. Trata-se de uma ressignificação discursiva que, partindo do antiprofissionalismo proveniente do gerencialismo e da lógica da livre concorrência no mercado, se difunde na sociedade e influencia os profissionais e a área de estudo das profissões, onde também ganha novos sentidos. Apesar dessa característica, os profissionais em organizações burilam o profissionalismo organizacional de forma a conquistar novos campos de atuação, em uma interação que não se reduz à subordinação intencionada pela corporação (Muzio e Kirkpatrick, 2011).

\section{A trajetória de institucionalização e as disputas em torno da profissionalização dos despachantes em São Paulo}

Este tópico apresenta a produção jurídica da norma sobre o despacho de documentos ao longo do século XX e as recentes disputas em torno dela.

As primeiras normativas sobre os despachantes em São Paulo partiram da prefeitura, que criou e regulamentou a atividade em $1926^{7}$, com quarenta vagas prenchidas

7. A lei 2.970, de 7 de maio de 1926, cria a classe dos despachantes municipais. O ato 2.650, de 7 de junho de 1926, regulamenta as funções e os cargos de despachantes municipais. 
por nomeação do prefeito, que detinha também a prerrogativa de demissão, em que os despachantes atuavam como intermediários entre as repartições municipais e os munícipes. Os assuntos de documentação de trânsito estavam previstos nessa legislação, além daqueles para aprovações de plantas e projetos de obras e aberturas de ruas, documentos e requerimentos para instrução e andamento de processos, certidões, alvarás, atenuação ou remissão de impostos, e recebimento de dinheiro dos cofres públicos. Em 13 de janeiro de 1931, o ato n. 55 do prefeito extinguiu a classe dos despachantes municipais, em sintonia com a visão predominante no contexto da Revolução de 1930, contrária aos privilégios profissionais e às reservas de mercado. Em 22 de outubro de 1947, o decreto 1.021 do prefeito instituiu novamente o quadro de despachantes municipais, desta vez com dez vagas, já sem a atribuição do trânsito. $\mathrm{O}$ Sindicato dos Despachantes do Estado de São Paulo, que foi instalado oficialmente em 27 de julho de 1937, obteve o reconhecimento de que seus filiados teriam os mesmos direitos e deveres do quadro de despachantes municipais, pelo decreto 1.066, de 29 de dezembro de 1948, do prefeito de São Paulo.

No estado de São Paulo, a primeira regulamentação para despachantes referia-se às atividades de registro e legalização de permanência de estrangeiros, no âmbito da Delegacia Especializada de Estrangeiros, inserida no decreto 11.782, de 30 de dezembro de 1940, que regulamentou a Superintendência de Segurança Política e Social.

No setor do trânsito, com a expansão deste mercado, criou-se o Código Nacional de Trânsito, em 1941, com a Diretoria de Serviços de Trânsito de São Paulo estabelecendo as disposições de atuação dos despachantes nesse segmento. A Secretaria de Segurança Pública também regularizou as atividades dos despachantes policiais nas repartições subordinadas a ela, em 7 de fevereiro de 1944. Já a lei 2.600, de 15 de janeiro de 1954, ampliou o escopo do ato anterior, regulamentando as atividades dos despachantes na Secretaria de Segurança Pública e criando a Seção de Fiscalização das Atividades dos Despachantes. Uma nova legislação estadual - os decretos 37.420 e 37.421, de 13 de setembro de 1993 - definiu as atribuições do Serviço de Fiscalização dos Despachantes e dispôs sobre suas atividades em todos os órgãos da administração pública, unificando as normativas anteriores.

$\mathrm{Na}$ esfera federal, que detém a competência para legislar sobre as condições para o exercício de atividades profissionais, os despachantes conseguiram em 2002 a lei 10.602, que criou o Conselho Federal e os Conselhos Regionais dos Despachantes Documentalistas ${ }^{8}$, mudando a condição da atividade como um serviço que era

8. Havia, no Brasil, em 2014, 29 conselhos federais profissionais, 27 exigindo formação técnica específica como credencial, entre esses o Conselho Federal dos Corretores de Imóveis. Apenas dois deles foram organizados sem a obrigatoriedade de diploma na área: o Conselho Federal dos Representantes Comerciais, criado em 1966, e o Conselho Federal dos Despachantes Documentalistas, aprovado 36 anos depois. 
concessão do Executivo para constituir-se em um sistema de conselho profissional, com regulamento próprio, código de ética, disciplina e estatuto. As lideranças que se mobilizaram pela aprovação dos conselhos tentaram delimitar no projeto de lei a reserva de mercado para o despacho de documentos na área de trânsito, mas esses artigos foram vetados pela presidência da República.

A criação do Conselho Regional dos Despachantes Documentalistas do Estado de São Paulo (CRDD-SP) teve impacto sobre a aplicação da lei estadual que havia regulamentado a profissão de despachante em 1993. Até a mudança do Detran-SP para a nova secretaria, em 2011, a concessão do serviço aos despachantes era controlada pelo Serviço de Fiscalização de Despachantes (SFD), na Divisão de Registros Diversos (Dird), parte da estrutura de apoio da Polícia Civil, na Secretaria Estadual de Segurança Pública. Esse serviço fiscalizava e regulamentava as atividades dos despachantes e de seus auxiliares no exercício de suas funções profissionais, até mesmo em relação às infrações administrativas. Competia ao $S F D$ a concessão e a renovação de alvará de funcionamento de estabelecimento e a expedição de crachá de identificação do despachante e seus auxiliares, credencial que dava acesso ao gerenciamento eletrônico dos serviços.

A legislação federal que criou o sistema de Conselho abriu as portas para a disputa jurisdicional entre o CRDD-SP e o Detran-SP pela habilitação, regulação e disciplinamento do exercício profissional. As resistências a ceder o controle para os conselhos eram sustentadas pelo veto presidencial à reserva de mercado e vinham dos delegados de polícia que fiscalizavam a atividade e de grupos de despachantes que achavam que o CRDD-SP complicava mais do que ajudava, ao ter poder para habilitar os pares. A clivagem entre os praticantes manifestava-se no apoio ao credenciamento ser atribuição do conselho regional ou manter-se sob o controle dos delegados de polícia.

Segundo o presidente do CRDD-SP, Francisco Castro Pereira, o Serviço de Fiscalização interrompeu a seleção de novos despachantes em 1992, concedendo apenas a renovação de alvarás.

Com o paulatino avanço no sistema de informatização dos serviços de emissão de documentos, de pagamento de taxas e multas, Imposto sobre Propriedade de Veículos Automotores (IPVA), licenciamento, entre outros, o mercado de trabalho dos despachantes e seus auxiliares foi encolhendo, e a concessão de novos crachás acompanhou isso. Por outro lado, vários dos serviços oferecidos pelos despachantes para lidar com a burocracia passaram a ser executados por grandes negócios privados, que ganharam concorrências públicas para atuar na desburocratização, como o Poupatempo, e na gestão do pagamento de taxas e licenciamento pelo sistema bancário. 
A estimativa da Pesquisa Nacional por Amostragem de Domicílios (PNAD) de 2009 foi de que 9.489 pessoas estavam ocupadas como despachantes documentalistas $^{9}$ no estado de São Paulo e 28.340 no Brasil. Em 2012, o CRDD-SP contava com 3.428 despachantes documentalistas registrados, dos quais $65 \%$ tinham mais de 50 anos e $18 \%$ eram mulheres. Quanto ao grau de escolaridade, o nível com maior concentração era o segundo grau completo, com $44 \%$, seguido do superior completo com $33 \%$.

Discursivamente, o profissionalismo foi apresentado pelas lideranças do CRDD-SP como o novo, a aposta na superação das práticas tradicionais vinculadas ao regime das concessões do estado. A ênfase era na autonomia, em contraposição à valorização que se dava a proteção do Detran-SP, em especial dos delegados no interior do estado. Em um mapeamento dos conflitos enfrentados na organização do Conselho encontramos, além desses já mencionados, as diferenças na forma de nomear a atividade (despachantes públicos, despachantes de trânsito, despachantes policiais) e a exclusividade sobre a denominação despachante documentalista, a amplitude das áreas de atuação (especialidades), as formas de conceber o fluxograma dos serviços passando ou não pelos órgãos de classe. Por um lado, esses conflitos jurisdicionais foram vocalizados por associações de despachantes que se organizaram em torno da Federação das Associações de Despachantes do Estado de São Paulo; por outro lado, pelo Conselho Regional e o Sindicato dos Despachantes do Estado de São Paulo.

As disputas em torno do modelo de profissionalização não esmaeceram porque seguem existindo brechas jurídicas que distribuem ganhos e perdas às visões concorrentes. A judicialização do conflito profissional deu vitória ao CRDD-SP no embate estadual com a lei 8.107, que invadiu prerrogativa federal de regulamentar profissões, reconhecendo que não havia fundamento na renovação anual do alvará de funcionamento no âmbito do Serviço de Fiscalização dos Despachantes, não cabendo a esse órgão a habilitação, o credenciamento, a realização de concursos públicos, a definição de atribuições, direitos, deveres, impedimentos e penalidades aos despachantes. Já o Detran-SP argumentou no Judiciário que não controlava a profissão, mas garantia segurança ao serviço oferecido à população, conseguindo preservar a renovação anual do alvará para acesso ao sistema online. Essas disputas transferiram-se junto com o órgão de trânsito para a Secretaria de Planejamento e Gestão, mesmo sem a participação dos delegados nesse novo gerenciamento.

O litígio do CRDD-SP em torno do monopólio profissional foi negado em decisão judicial, favorecendo o pleito de algumas associações de despachantes do interior do estado. $\mathrm{O}$ acórdão do Tribunal Regional Federal - 3 ${ }^{\mathrm{a}}$ Região posicionou-se

9. Código n. 4.231 na Classificação Brasileira das Ocupações (Сво). 
contrário ao controle profissional, mantendo "obstada a delegação do poder de polícia, de tributar e de punir, no que tange ao exercício da atividade profissional de despachante documentalista" e "conferiu aos referidos Conselhos apenas o poder de representar os profissionais junto a órgãos e entidades, sendo vedado - por ausência de previsão legal - estipular requisitos ou entraves aos pedidos de inscrição que thes forem endereçados" ${ }^{10}$. A distribuição de vitórias e derrotas entre os litigantes segue na judicialização da disputa no Supremo Tribunal Federal.

As lutas concorrenciais minam a construção do domínio dos grupos que recorrem ao discurso do profissionalismo para contrastá-lo com o "jeitinho" de lidar com a burocracia. Ainda não conseguiram produzir coesão ou hegemonia interna nem autonomia em relação ao credenciamento no Detran-SP, que operacionaliza concessão desse serviço.

O Conselho Regional dos Despachantes Documentalistas de São Paulo detém o uso dessa nomeação profissional, oferecendo cursos de qualificação e carteira de identificação para atuação nos órgãos públicos, mas não conseguiu transformá-los em credencial para reservar o mercado. Os despachantes que contestam esse monopólio registram seu alvará no Detran e exercem a atividade como despachante público ou outra denominação.

O estatuto do CRDD-SP classifica quatro tipos de vínculos no exercício da ocupação: o despachante documentalista (autônomo), o despachante estagiário, as sociedades dos empresários despachantes e o despachante empregado (Guia de referência, s. d.). Além das hierarquias na área serem atravessadas pelo tamanho do estabelecimento e pelos tipos de vínculos, a especialidade diferencia a relação entre os despachantes, já que o Conselho luta efetivamente pela jurisdição na área de trânsito, para os atos privados de despachante documentalista.

\section{Perfil dos despachantes documentalistas de São Paulo}

Neste tópico serão apresentados os dados dos perfis dos 3.428 despachantes filiados ao CRDD-SP, em 2012, e os resultados de um survey realizado pela pesquisa em 2013, com 107 despachantes atuantes no estado de São Paulo, havendo entre estes profissionais filiados ou não no Conselho Regional. Nos próximos tópicos serão aprofundadas as análises sobre a atuação profissional e as opiniões dos despachantes a respeito da profissão.

Entre os inscritos no CRDD-SP, 82\% são homens, 65\% nasceram antes de 1960 , revelando-se um grupo em processo de envelhecimento. Apenas 13\% nasceram de-

10. Acórdão do TRF - 3a Região, publicado em 27/5/2013. 
pois de 1971, mostrando as dificuldades de renovação. Quanto aos anos de estudo, predomina o segundo grau completo (44\%), que, somado aos filiados com escolaridade inferior a esta, chega a 55\% do grupo; $34 \%$ concluíram o ensino superior.

A área de atuação profissional desses filiados distribui-se pelo estado de São Paulo, mas a capital destaca-se com 24\%; os municípios da área metropolitana somam 18\%, e a região de Campinas, $15 \%$. Eles são predominantemente despachantes autônomos (77\%), havendo $23 \%$ de pessoas jurídicas entre os sócios.

Já o quadro formado pelos 107 respondentes do survey difere do total dos sócios, uma vez que o retorno dos questionários enviados foi bem baixo, mesmo quando se insistiu no contato pessoal para o preenchimento. Por outro lado, os dados dos questionários permitem uma visão mais ampla das mudanças que o grupo enfrenta, com mais informações sobre o perfil social, profissional e as opiniões dos entrevistados.

Os respondentes são majoritariamente homens (89\%), brancos (95\%), casados ou em união civil estável (84\%). A faixa etária que apresenta maior concentração é a que nasceu entre 1951 e 1970, com 62\% dos entrevistados; outros 25\% nasceram antes desse período. Apenas 6\% deles nasceram fora do estado de São Paulo.

Com relação ao nível de escolaridade, predomina o nível superior completo, com 53\%; acrescentando-se aquele com formação superior incompleta tem-se 77\% da amostra. A área do conhecimento de maior destaque entre eles é a das ciências sociais aplicadas, em especial os cursos de administração e de direito.

Com relação ao nível de escolaridade dos pais, a maior proporção está entre os despachantes cuja mãe e o pai possuem até o ensino fundamental I completo, o que demonstra a origem social mais humilde e a mobilidade educacional dos filhos. A porcentagem do nível educacional dos pais é bastante próxima, havendo $58 \%$ das mães e $54 \%$ dos pais com instrução até o equivalente ao antigo ensino primário.

\section{Atuação como despachante}

O questionário permite conhecer o cotidiano da atuação do despachante documentalista, as mudanças que ocorreram ao longo da trajetória, as motivações para a escolha profissional, o período de início na atividade, os serviços mais produtivos no passado e no presente e a remuneração obtida, entre outros aspectos da prática.

Como o tamanho do grupo se retraiu nas últimas décadas, a amostra tem concentração em faixas etárias mais elevadas e com um longo tempo de ingresso na atividade. Assim, 81\% dos respondentes começaram a trabalhar com despacho de documentos entre os anos de 1970 e 1999 . Apenas 5\% deles adentraram a ocupação no século XXI. Considere-se que este início não ocorreu logo como despachante: $64 \%$ foi anteriormente auxiliar de escritório ou auxiliar de despachante/preposto. 
Para exercer a função de despachante, $70 \%$ fizeram concurso promovido por algum órgão público, como o Detran e a Secretaria de Segurança Pública. Alguns obtiveram o crachá nesses órgãos, mas sem o concurso, porque houve períodos em que isso foi possível para quem atuava como preposto. Outros assumiram a credencial de parente ou trabalham sem ela. O formato mais recente de obtenção da carteirinha via curso e prova no CRDD-SP foi observado para $18 \%$.

As principais motivações para ser despachante foram a influência da família e o fato de conhecer a área por já trabalhar nela antes, ambas com $31 \%$ de respostas, seguida da vocação ou aptidão pessoal (21\%). Nesse sentido, difere dos discursos profissionais que priorizam as escolhas vocacionalmente motivadas.

Com relação à cidade onde atuam, os respondentes estavam menos concentrados na capital e área metropolitana, que juntas somaram 22\%, mostrando-se mais espalhados pelo interior, com $25 \%$ na região central do estado e $21 \%$ em Campinas e entorno. Os estabelecimentos nos quais os despachantes trabalham localizam-se em imóveis comerciais para $91 \%$ da amostra, havendo $6 \%$ de escritórios na própria residência e 3\% de profissionais exercendo a função em sociedade de despachantes. Portanto, a grande maioria trabalha sozinha (77\%). Quando conta com funcionários, destaca-se o trabalho dos prepostos (38\%), seguido dos auxiliares de escritório, de faxina, recepcionista e/ou office-boy. Em 48\% dos casos, o despachante trabalha ou emprega familiares, em especial filhos e cônjuge como auxiliar de escritório ou atuando como despachante.

A remuneração obtida com os serviços de despacho de documentos concentra-se na faixa de $\mathrm{R} \$ 2.000,00$ a $\mathrm{R} \$ 6.000,00^{11}$, para $48 \%$ dos respondentes; $12 \%$ da amostra informaram receber menos que isso por mês com a atividade e $25 \%$ obtinham como despachante mais de $\mathrm{R} \$ 6.000,00$ mensais.

\section{Percepções sobre a profissão}

Os despachantes documentalistas estão concentrados nos assuntos de trânsito. Isso decorre do fato de esta ser a área com maior oferta de clientes, já que o trânsito e a frota de veículos apresentam enorme crescimento, bem como requerem conhecimento da legislação específica e credenciamento no órgão público responsável, produzindo certa especialização. Isso fica evidente ao se observar os tipos de documentos que eles oferecem a seus clientes.

11. Na ocasião da coleta dos dados, em 2013, o câmbio da moeda era us $\$ 1,00=\mathrm{R} \$ 2,00$, e o valor do salário mínimo era de $\mathrm{R} \$ 678,00$. 
Os entrevistados demonstraram percepções aguçadas sobre as diferenças no trabalho que realizavam no passado e o que se oferece no presente. Essa mudança se materializa tanto no tipo de serviço, que é mais requisitado, como no volume dessa demanda, que foi reduzido significativamente. Como se trata de um grupo vinculado ao trânsito, o principal serviço que realizavam regularmente era o licenciamento de veículos. Com a frota em expansão e a obrigatoriedade da licença anual, que consumia tempo e energia do proprietário para reunir a documentação, enfrentar filas, superar entraves burocráticos e repetir a rotina, a garantia de clientela estava assegurada. Com a possibilidade de licenciar eletronicamente os veículos, através de pagamento nos caixas automáticos dos bancos e recebimento do licenciamento em casa, com entrega pelo correio, o procedimento ficou mais rápido, sem a necessidade de recorrer à intermediação do despachante. A demanda anual por esse serviço retraiu-se, sendo mais frequente utilizá-lo apenas no ato de compra do carro. Assim, $65 \%$ dos despachantes entrevistados afirmaram que o licenciamento foi a principal fonte de serviço, mas atualmente é o maior volume de trabalho para apenas $28 \%$ deles. Já a transferência do veículo para um novo proprietário tornou-se o documento despachado com mais frequência, mas isso não tem a mesma regularidade que teve o licenciamento anual. Fora do trânsito, os serviços prestados seguem pouco expressivos em termos de volume.

O Gráfico 1 apresenta os serviços que respondem pelas duas maiores menções em termos de volume de trabalho que os despachantes fizeram no passado e aquelas que eles fazem atualmente.

O questionário procurou detectar as práticas que os despachantes utilizavam e valorizavam para realizar com sucesso suas atividades, criando laços de confiança e conquistando novos clientes. Cientes da existência do "jeitinho" mencionado por alguns despachantes em entrevistas qualitativas, incluímos entre as alternativas dessa questão a menção aos pagamentos informais a funcionários e autoridades para obtenção de favores. Essa inclusão gerou crítica por parte de algumas lideranças, que entendiam isso como ofensa ao trabalho que realizavam, procurando contrapor-se a essa imagem que o formulário incorporava. Também distinguiam a corrupção, que o ato de pagar desnuda, da gentileza de oferecer um presente ao delegado ou uma lembrança ao funcionário da repartição. Com exceção desse episódio, no trabalho de campo não registramos resistência a responder a essa pergunta, embora ela possa ter sido um fator para desmotivar as lideranças a divulgar a pesquisa e solicitar a colaboração dos despachantes em preenchê-la.

Como pode ser observado no Gráfico 2, os aspectos mais valorizados pelos entrevistados para a boa atuação profissional são: conhecer as tecnologias informacionais específicas para o tipo de trabalho, conhecer os caminhos da tramitação dos docu- 
GRÁFICO 1

Distribuição dos dois maiores volumes de trabalho no passado e no presente, mencionados pelos despachantes, segundo o serviço realizado, em números absolutos e em porcentagem

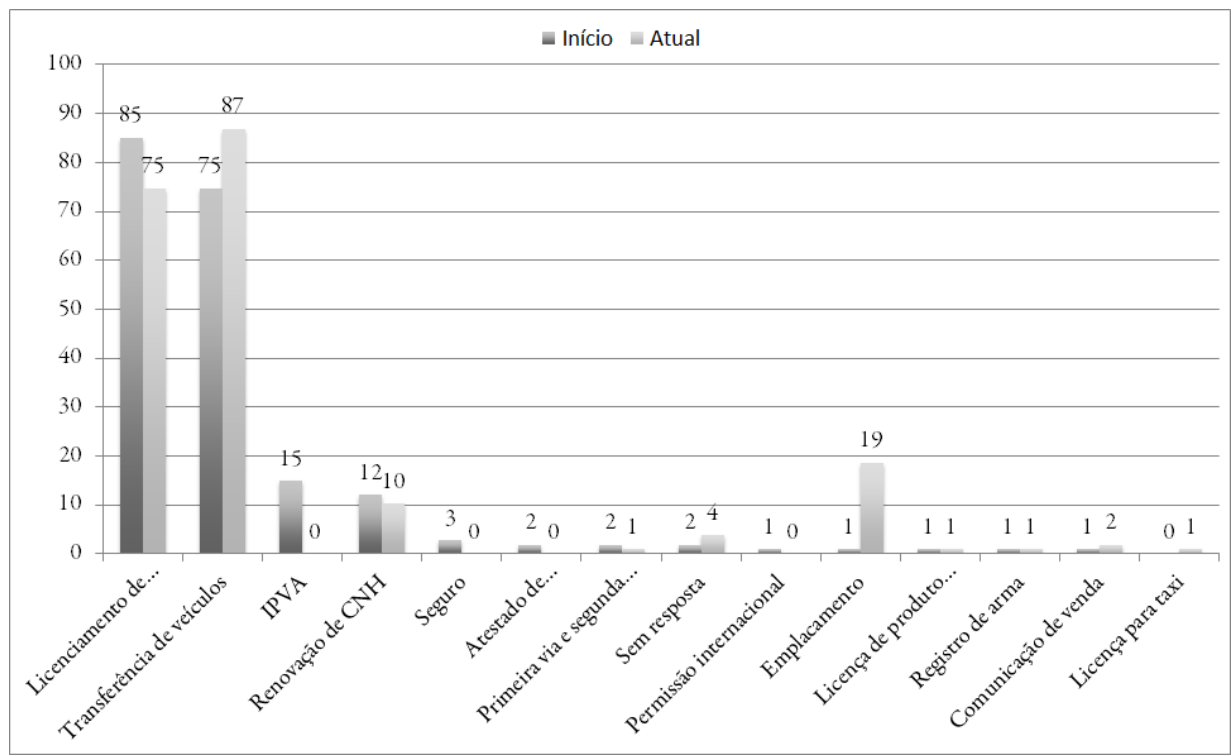

Fonte: Bonelli (2014).

GRÁfICO 2

Distribuição das práticas para atuação dos despachantes segundo a importância para a realização do trabalho, em números absolutos e em porcentagem

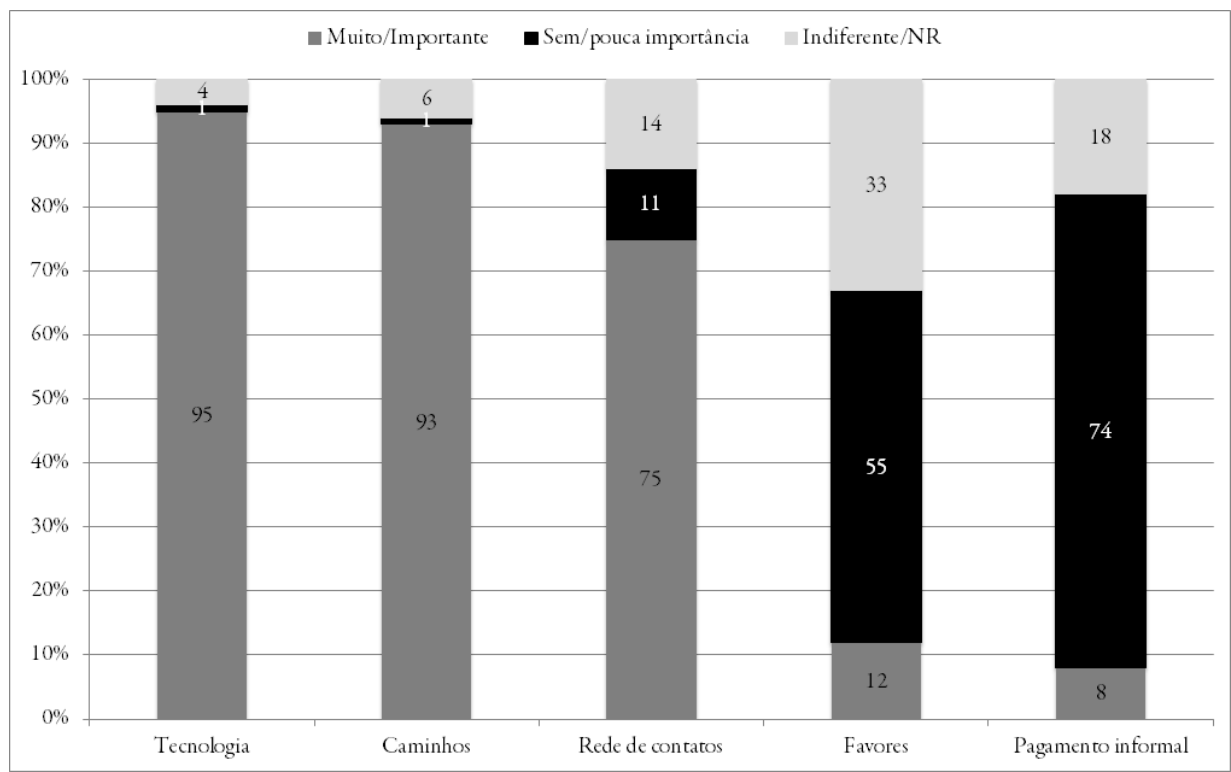

Fonte: Bonelli (2014). 
GRÁfICO 3

Distribuição da influência de determinadas práticas sobre a atuação dos despachantes, em números absolutos e em porcentagem

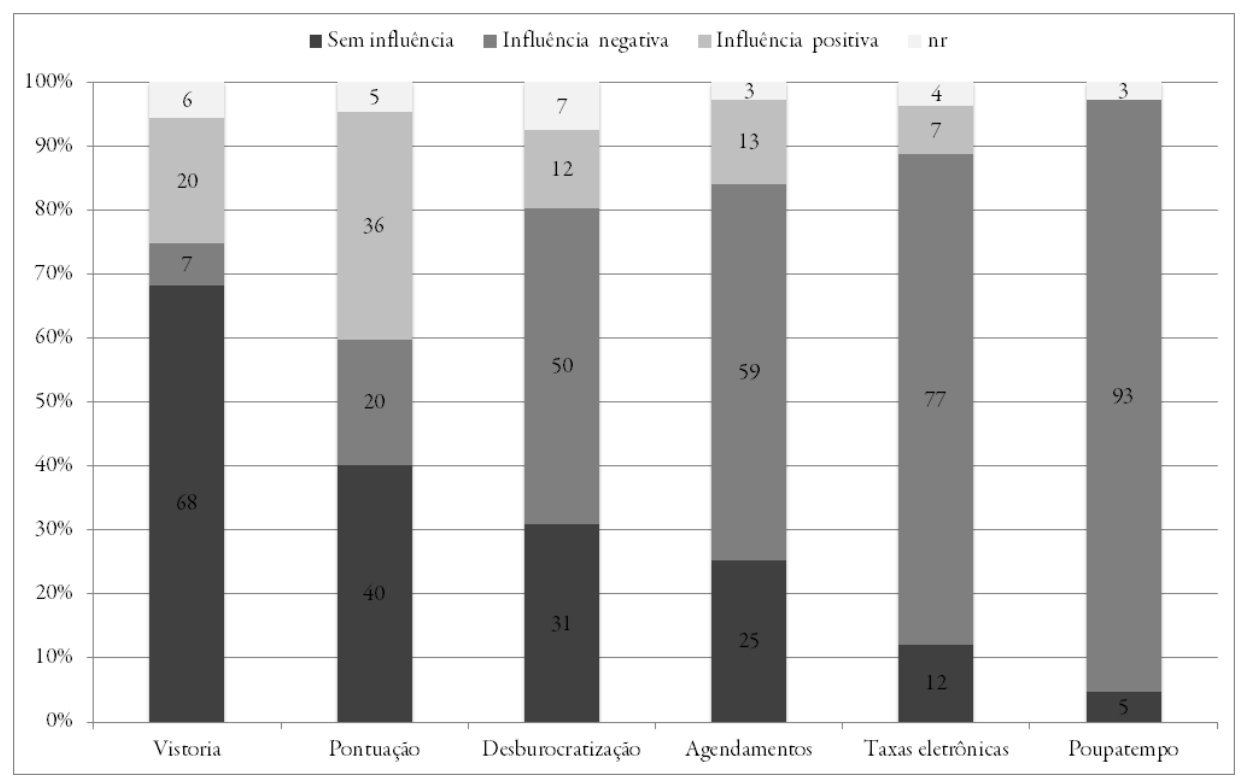

Fonte: Bonelli (2014).

mentos e possuir rede de contatos nos órgãos públicos onde atuam. Para o desempenho do trabalho, o pagamento informal e a troca de favores têm pouca importância ou não têm importância para a maioria dos respondentes. As três alternativas mais pontuadas combinam conhecimentos especializado, tácito e prático, permeados por laços sociais. Assim, eles mesclam conteúdos impessoais do profissionalismo com ideários personalizados pelos vínculos de classe e pelo conhecimento tácito do labirinto da burocracia.

Os despachantes foram mais incisivos em apontar os fatores que influenciaram negativamente sua atuação profissional do que os aspectos positivos. Entre as alternativas apresentadas no questionário, a criação do Poupatempo lidera a influência negativa. A perda da clientela que migrou para os serviços eletrônicos e o agendamento prévio para atendimento nos postos fixos existentes no estado de São Paulo tornaram imbatíveis essa concorrência ao fornecer acesso aos documentos com agilidade (Gráfico 3).

O grupo de entrevistados tem uma nítida percepção da falta de reconhecimento da relevância da atividade. Para 65\% deles, houve diminuição do prestígio do serviço do despachante no presente em relação ao que tiveram no passado. Entre os motivos apontados para isso, citaram os profissionais desonestos, a propaganda 
pejorativa sobre os despachantes e a imagem de corrupção; o sistema informacional, o Poupatempo e o licenciamento nos bancos; a economia por parte dos clientes providenciando seus documentos; a falta de importância dada pelo Estado; pouco reconhecimento; péssimo negócio; profissão não regulamentada; burocracia estatal e procedimentos mais burocráticos para os despachantes.

O prestígio do despachante permaneceu o mesmo para 17\% dos respondentes. As justificativas para essa visão foram: o prestígio permanece, mas o faturamento cai; nunca teve prestígio e, portanto, permanece a mesma coisa; é ainda uma classe reconhecida; a seriedade e o profissionalismo.

Para os $18 \%$ que fizeram uma avaliação positiva, identificando aumento no prestígio da atividade, as razões apontadas destacam valores normativos do processo de profissionalização: a prestação de serviços realizada de forma honesta e eficaz; o despachante é ainda necessário; o profissionalismo; o cliente busca informações seguras com os despachantes; confiança; facilidades para o particular; união entre os despachantes; e o fluxo de veículos.

Algumas lideranças dos despachantes no estado de São Paulo foram entrevistadas qualitativamente pela pesquisa. Esses encontros deram visibilidade aos conflitos sobre os caminhos para a profissionalização, em especial em torno do sistema de conselhos. Tais lutas concorrenciais estavam bastante polarizadas entre líderes tradicionais do grupo, despachantes com longa participação em posições de representação no sindicato e em associações de despachantes de cidades do interior do estado. As lideranças sindicais mobilizaram-se na criação do CRDD-SP e enfrentaram disputas judiciais fomentadas por segmentos internos à profissão, que questionavam a constitucionalidade das atribuições do Conselho, propondo contrapor a este uma federação. Assim, o questionário teve a preocupação de abordar as percepções do grupo sobre suas organizações profissionais, procurando auferir o conhecimento, a confiança e a adesão.

Do total de entrevistados, $47 \%$ declararam ser membro de alguma entidade profissional, incluindo nesta lista o CRDD-SP, o Sindicato dos Despachantes de São Paulo e diversas associações municipais.

A confiança dos entrevistados no sindicato e no sistema de conselhos apresentou-se equilibrada, em torno de 50\%, sendo levemente maior para o CRDD-SP, que está no centro do conflito das lideranças profissionais do estado.

O sindicato e o conselho paulistas se apoiam mutuamente. Quando o CRDD-SP foi organizado, em decorrência da aprovação do Conselho Federal, em 2002, o então presidente do Sindicato dos Despachantes do Estado de São Paulo, Francisco Castro Pereira, foi eleito para a presidência do CRDD-SP, acumulando a direção das duas entidades desde então. Elas funcionam no mesmo endereço. 
GRÁfICO 4

Distribuição da confiança dos entrevistados nos órgãos de classe citados segundo o grau, em números absolutos e em porcentagem

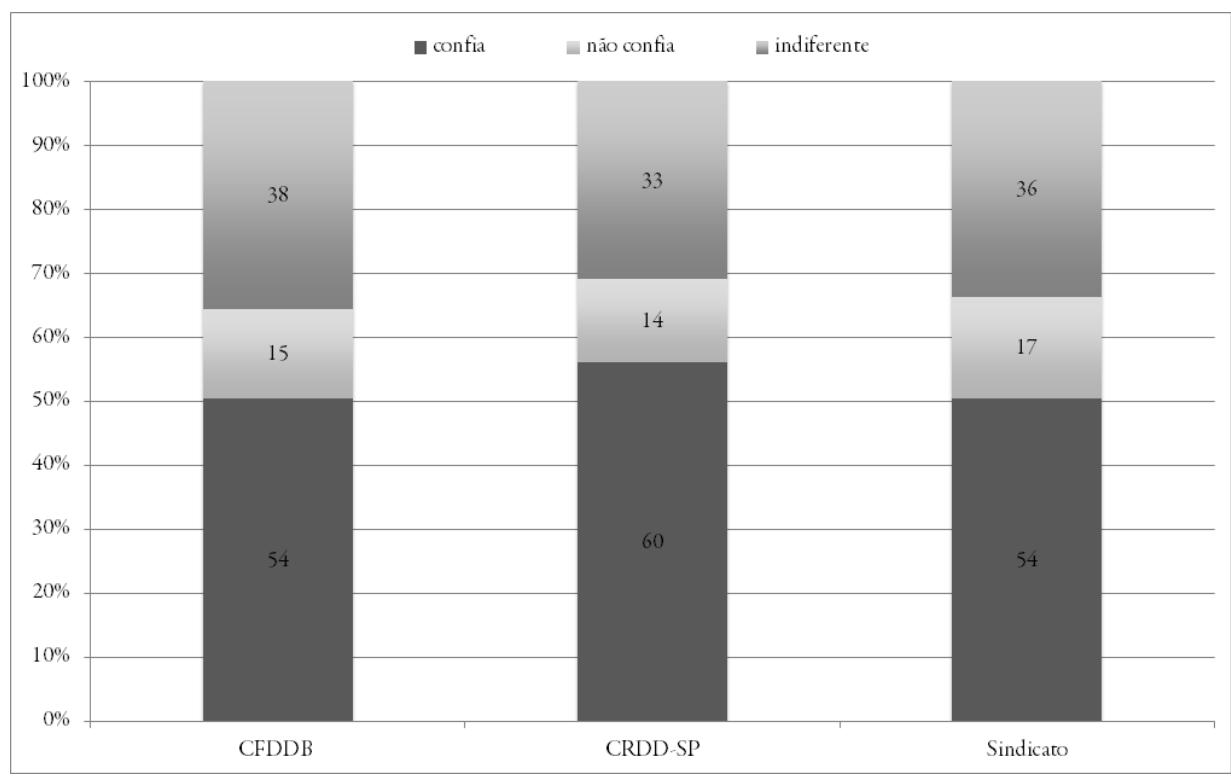

Fonte: Bonelli (2014).

Aos problemas relativos à auto-organização do grupo de despachantes se somam os indicadores do perfil social, da atuação cotidiana e das percepções sobre a atividade que constituem um cenário de desafios para a profissionalização, dando mais visibilidade às fragilidades desse processo no presente (Gráfico 4).

Finalizando o questionário, muitos foram os comentários livres registrados pelos entrevistados, revelando a disposição em se manifestarem sobre a situação da profissão de despachante documentalista. Em síntese, sobressai a responsabilização do governo pela situação de extinção da profissão, com a diminuição das possibilidades de trabalho e o encolhimento do grupo por falta de novos concursos. Quanto à representação profissional, mencionaram-se a contínua falta de união dos despachantes, a crítica aos conflitos entre o CRDD-SP e o Detran-SP, a importância de o CRDD-SP, além de recolher anuidades, fazer campanhas para melhorar a profissão e a necessidade de fiscalização eficiente e de controle profissional, combatendo a corrupção e o trâmite ilegal de documentos. Quanto à clientela, ganharam destaque a elevada competição para obter serviços, os benefícios que os despachantes oferecem como facilitadores dos cidadãos, o elo de ligação com as repartições públicas e a satisfação e confiança do público. 
A dimensão valorativa foi novamente acentuada, apontando a falta de reconhecimento e respeito até mesmo entre os pares, a queda de prestígio, a desvalorização, o predomínio do dinheiro sobre os valores morais e éticos, a corrupção do Estado e a caça às bruxas que acontece com os despachantes. Nos aspectos positivos, reafirmaram que a profissão é nobre, que tem profissionais qualificados, que amam o que fazem, que a atividade é importante e atrai interesses de outros grupos, como os cartórios, a Federação Brasileira de Bancos, a Federação Nacional de Distribuição de Veículos Automotores e a Federação Nacional das Empresas de Seguros Privados e de Capitalização.

\section{Considerações finais}

As reformas da gestão pública em São Paulo relacionadas com a terceirização dos serviços de emissão de documentos acertaram em cheio o trabalho dos despachantes. As relações dos órgãos públicos com a população no que diz respeito ao acesso à cidadania documentada prescindiram de tal intermediação. Em substituição ao modelo então vigente, que requeria os facilitadores para superar os obstáculos burocráticos existentes nessas repartições, vieram as licitações públicas para a realização do programa Poupatempo e a troca dos despachantes pelas empresas que ganharam as concorrências - bancos e caixas eletrônicos. Assim, como observado por um entrevistado, a atividade de despacho de documentos é importante e atrai interesses de grandes negócios. Os despachantes é que foram deslocados desses serviços nos novos formatos institucionais e de realização do trabalho. Na pesquisa, as percepções dos entrevistados sobre a situação do grupo demonstram que eles sabem do que estão falando e responsabilizam principalmente o Estado pelo quadro atual. Acham que foram amigos dos governos, e em retorno sentem-se abandonados.

Em alternativa a esse cenário, trilham caminhos familiares: manuseiam profissão e política como podem, combinando projetos de profissionalização focados no conhecimento dos despachos e na autonomia perante os órgãos públicos, com pedidos de ajuda ao governo, vindo de cima, e aos políticos, vindo de fora do mundo das profissões. O Estado se materializa nas relações de longa duração com agentes e autoridades de órgãos públicos, em especial os delegados de polícia. Como os governantes não são amigos, a política que está acessível é a dos deputados, a quem pedem apoio para encaminharem projetos de lei constituindo conselhos, federações, monopólios que acabam derrubados no Executivo ou no Judiciário.

Para o sucesso no profissionalismo ocupacional, o grupo precisa deter recursos quanto ao domínio de conhecimento especializado e amplas aspirações de legitimidade (Muzio e Kirckpatrick, 2011, p. 391). Ambas as condições estão ausentes 
na ocupação: 66\% dos despachantes não possuem escolaridade de nível superior completo, e a imagem pública da atividade mina tal pretensão. A saída de cena do trabalho sujo não consegue dar lugar ao mandato moral, e as relações de dependência do Estado não são suplantadas pelo profissionalismo cívico como vimos no ideário dos advogados. Os despachantes não têm um projeto, mas muitos deles esperam do governo um projeto de profissão: o profissionalismo organizacional.

Como o profissionalismo organizacional não produziu os valores normativos que deram certa coesão às profissões, verifica-se entre os despachantes intensos conflitos jurisdicionais que estão sendo decididos nos tribunais.

A sociologia das profissões incorpora em seu arcabouço conceitual o profissionalismo organizacional, focalizando principalmente as relações dos profissionais nas organizações. Porém, os despachantes documentalistas no trânsito tradicionalmente atuam de maneira solitária; apenas um grupo bastante restrito de sociedades prestam serviços a concessionárias.

Os despachantes envolvem-se com a burocracia pública, conhecem os meandros para expedir os documentos nesses órgãos e sobrevivem desses serviços, mas a maioria não trabalha em organização, exercendo a atividade sozinho, em pequenos escritórios. Aspiram à profissionalização, que ampliaria o domínio de tecnologias informacionais e da tramitação de documentos, mas sabem das dificuldades de avançar o conhecimento em um grupo que envelhece sem se renovar; produzem alguma identificação com conteúdos do profissionalismo, como a autonomia, a confiança, mas estão carentes de reconhecimento público, configurando um quadro que inviabiliza a obtenção do profissionalismo ocupacional. Promovido e controlado pelo Estado, tal profissionalismo entra em cena principalmente para aqueles que não legitimam o Conselho: preferem os órgãos públicos no controle do grupo do que lideranças concorrentes, que constituem novas hierarquias e instâncias de fiscalização.

Os valores normativos do profissionalismo ocupacional não são partilhados pelos despachantes. Ele é constitutivo dos vínculos que giram em torno de colegas e destes com seus clientes. A prática solitária, com pouca convivência em associações coletivas, a elevada competição individual por clientes, a perda de tarefas para novas organizações e a ausência de renovação fazem com que os despachantes sintam a vulnerabilidade de sua posição e pressintam a sua extinção.

Em suma, a via da profissionalização surge com o temor da extinção pela perda de várias tarefas para corporações, em função das reformas promovidas no âmbito estatal. Embora o discurso do profissionalismo organizacional embase os estereótipos negativos sobre os despachantes, isso não é vivenciado assim pelo grupo, que concentra sua crítica na esfera política. É no âmbito moral que os despachantes buscam revalorização profissional, mas não possuem o conhecimento que sustenta 
o profissionalismo ocupacional. Assim, este adquire conteúdo afetivo em apego ao passado, à rotina dos documentos, à rede de conhecidos no labirinto das repartições, aos pedidos de apoio para as autoridades públicas.

O maior obstáculo à aspiração de profissionalização é que o conhecimento tácito que dominam não possui hoje o valor que tinha quando o "jeitinho" era a forma da sociedade obter serviços públicos. $\mathrm{O}$ acesso à cidadania documentada e à informação sobre os atendimentos no Poupatempo é o combustível aos julgamentos morais sobre o trabalho sujo ou sobre o atraso das práticas burocráticas que travam o desenvolvimento. O profissionalismo potencializa ocupações que dispõem de recursos para sustentar sua pretensão, como o domínio de uma base de saber para oferecer à sociedade, relacionando o interesse específico ao interesse público, a força para reservar o mercado com o apoio de aliados poderosos. Os despachantes estão tentando se reinventar nesse aspecto, mesclando profissionalismo, organizações e política; o novo e o velho; o moderno e o tradicional; o impessoal e as redes de conhecidos. Buscando alguma segurança nos riscos que correm na contemporaneidade, os despachantes manuseiam laços sociais, burocracia, Estado e profissões.

\section{Referências Bibliográficas}

Arantes, Paulo Eduardo. (2011), "Sale boulot: uma janela sobre o mais colossal trabalho sujo da história: uma visão no laboratório francês do sofrimento social”. Tempo Social, 1 (23): 31-66. BeCKer, Howard S. (2009), Outsiders: estudos de sociologia do desvio, Rio de Janeiro, Zahar. Bonelli, Maria da Gloria. (2014), "Street level brokers: shrinking the occupation of despachantes in an era of global managerialism”. XVIII International Sociological Association World Congress, Research Committee 52, Yokohama, 13-19/7.

DaMatta, Roberto. (1984), O que faz o Brasil, Brasil? Rio de Janeiro, Rocco.

Domingues, José Maurício. (2008), “Patrimonialismo e neopatrimonialismo”. In: Avritzer, Leonardo et al. (orgs.). Corrupção: ensaios e criticas. Belo Horizonte, Editora UfMG, pp. 187-192.

Evetts, Julia. (2013), “Professionalism: value and ideology”. Disponível em http://csi.sagepub. com/content/61/5-6/778, consultado em 29/5/2016.

Freidson, Eliot. (2001), Professionalism, the third logic. Cambridge, Polity.

GUIA DE REFERÊNCIA do Despachante Documentalista. (s. d.), São Paulo, Conselho Federal dos Despachantes Documentalistas do Brasil/Conselho Regional dos Despachantes Documentalistas do Estado de São Paulo.

Halliday, Terence. (1999), "Politics and civic professionalism: legal elites and cause lawyers". Law \& Social Inquiry, 4 (24): 1013-1060.

Hughes, Everett. C. (1984), The sociological eye. New Brunswick, Transaction. 
Mathieu-Fritz, Alexandre \& Bercot, Régine. (2008), Le prestige desprofessions et sesfailles. Paris, Hermann.

McClelland, Charles E. (1990), "Escape from freedom? Reflections on German professionalization 1870-1933". In: Torstendahl, Rolf \& Burrage, Michael. (orgs.). The formation of professions: knowledge, state and strategy. Londres, Sage, pp. 97-113.

Muzio, Daniel \& Kirkpatrick, Ian. (2011), "Introduction: professions and organizations: a conceptual framework". Current Sociology, 4 (59): 389-405.

SAKs, Mike. (2012), "Defining a profession: the role of knowledge and expertise". Professions \& Professionalism, 1 (2): 1-10. Disponível em https://journals.hioa.no/index.php/pp/article/ view/151/355, consultado em 16/3/2012.

Teciano, Livia Carvalho Gutierrez. (2014), Inovação em serviços públicos: o caso Poupatempo. São Carlos, dissertação de mestrado, Programa de Pós-Graduação em Ciência, Tecnologia e Sociedade, UFSCar.

\section{Resumo}

Os despachantes documentalistas na era do profissionalismo organizacional

O artigo analisa o processo de profissionalização dos despachantes documentalistas após o impacto da terceirização desses serviços para o Poupatempo, com a introdução de processos globalizantes de acesso a cidadania documentada, que encolheram o mercado da intermediação. Em substituição ao modelo tradicional das relações entre Estado e sociedade para obtenção de serviços públicos que envolviam o "jeitinho", os despachantes buscam o profissionalismo organizacional e a criação de conselhos estaduais e federais. Além das lutas concorrenciais entre os pares que se desdobram na judicialização desses conflitos, eles enfrentam a condenação moral, que se seguiu à perda de relevância social da atividade. A pesquisa baseia-se em fontes documentais primárias e secundárias, em um survey com 107 despachantes e em entrevistas qualitativas com lideranças profissionais. Palavras-chaves: Profissionalismo organizacional; Despachantes; Trabalho sujo. 


\section{Abstract}

Document clearing agents in the age of organizational professionalism

The article focuses on the professionalization process of document clearing agents (despachantes), as result of these services downsizing with the introduction of globalizing processes of access to documented citizenship, which have shrunk the job market for brokers. Instead of the traditional "easy way" to provide these services, the despachantes are searching for organizational professionalism, and have founded national and regional councils. Besides facing intra-professional competition and the judicialization of these conflicts, they also have to cope with moral judgments of their practices after losing its social role. The field research gathers data from primary and secondary resources, from a survey with 107 respondents, and qualitative interviews with professional leaderships.

Keywords: Organizational professionalism; Document clearing agents; Dirty work.

Texto recebido em 21/10/2015 e aprovado em 21/10/2015. DoI: 10.11606/0103-2070. ts.2016.106228.

MARIA DA GLORIA BONELLI é professora sênior do Programa de Pós-graduação em Sociologia da Universidade Federal de São Carlos. E-mail: gbonelli@uol.com.br. 


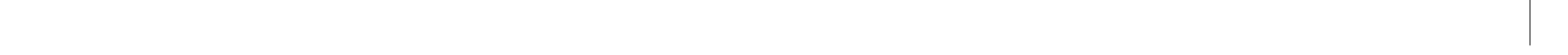

